Article

\title{
On Glass, in Glass, of Glass: Some Developments in the Combination of Glass and Printmaking
}

\section{Kevin Petrie}

School of Art and Design, The University of Sunderland, Sunderland SR1 3SD, UK;

kevin.petrie@sunderland.ac.uk

Received: 21 December 2018; Accepted: 1 February 2019; Published: 6 February 2019

check for

updates

\begin{abstract}
This paper considers some examples of creative glass practice and research at the 'overlap' of two distinct sectors of art and design- 'glassmaking' and 'printmaking'. The unique properties of glass mean that printed imagery can be applied on the glass surface, encapsulated within the glass form and can even be made of glass. Case studies are given relating to each of these areas. In particular, the article offers some reflections on the development of glass and print over the last twenty or so years. These reflections are based on the author's perspectives as an artist, teacher, and researcher. Following a historical overview, case studies are given on the work of Kevin Petrie, Rachel Welford, Miyoung Jung, Jeffrey Sarmiento, and Kathryn Wightman. All of these makers are associated with the Glass and Ceramics Department of the University of Sunderland, UK, based in National Glass Centre, but all have made wider impacts beyond the UK.
\end{abstract}

Keywords: glass; print; screen-printing

\section{Introduction}

For over two millennia, glass objects have been carriers of an added layer of meaning through the application of images in the form of pictures, patterns and texts. Today, artists are exploiting the unique properties of glass to create decorative and sculptural works, in which, image, object, and material are combined. This creates great visual and metaphoric potential for the artist and new ways of presenting 'the image'.

As a creative medium used by individual artists, as opposed to the industry, glass emerged through the 'studio glass movement' in the 1960s, and is now a significant strand of art and design worldwide. The creative use of glass might be considered in three broad areas: 'Hot Glass' (glass blowing), 'Kiln-formed Glass' and 'Architectural Glass'.

Hot glass processes involve molten glass being taken directly from a furnace and manipulated in a hot state to create forms. This often involves 'glass blowing', whereby vessels are formed from 'bubbles' of glass on a blowing iron. Another common method is sand-casting where molten glass is poured into a sand mould to create forms.

Kiln forming is the term used to describe a number of methods where by glass in a cold state is heated inside a kiln, often in or over some kind of mould, again to create a form. This can involve casting glass, 'slumping' flat glass into a form, and fusing sheets or granules of glass together.

Architectural glass is a broad term often used to describe flat glass used in architectural contexts such as stained glass windows. This term can also be related to 'architectural' or flat glass processes such as painting, acid etching, sandblasting and printing which can be used to form non-architecture based 'autonomous' panels for gallery exhibition.

'Printmaking' is a broad term used to describe a range of methods for reproducing artwork. These methods include etching, screen-printing, lithography and relief printing. In most cases, ink is applied onto a printing plate or through a stencil, and transferred to paper to reproduce an image. Although 
printmaking techniques offer the advantage of reproducing pictures, text and patterns, they also offer distinctive aesthetic effects that artists might choose to exploit over the benefits of multiple production. Ivins (1988, p. ix) unpacks this through his 'elementary introduction to the appearances (the outward and visible signs) of prints'.

The key difference between printing onto paper and onto alternative substrates, such as glass or ceramics, is that vitrifiable inks need to be used, which can be bonded permanently to the glass or ceramic surface through the action of heat in a kiln. These inks usually consist of enamelscomparatively low firing glass frits containing metallic oxides as the colouring agent.

\section{A Personal Perspective}

To a certain extent this paper offers a personal reflection on the development of glass and print over the last twenty or so years. These reflections are based on my perspectives as an artist, teacher and researcher. In the early 1990's, I was a student on the BA (Hons) Illustration course at Harrow, University of Westminster. This was the first degree in the UK with the title Illustration and took a very broad approach to the subject. During my second year on the programme, a visiting lecturer told me about the ceramic transfer printing process, which I subsequently learnt and started to use to apply my illustrations to ceramic tableware. This led me to the Royal College of Art and an MA in Ceramics and Glass. Here I started to see the potential of glassmaking processes and printmaking, and I developed a body of kiln-formed pieces in which screen-printed ceramic transfers were encased in kiln formed mask like forms. I went on to complete a PhD at the Centre for Fine Print Research, University of the West of England, Bristol, where I helped to develop a water-based system for printing onto ceramics. Following this, I became a lecturer in ceramics at the University of Sunderland. Sunderland has a long-standing glass and ceramics department, and in my early years there, I again started to consider the potential of combining glass and print. I brought this together in my 2006 handbook 'Glass and Print' (Petrie 2006b).

My artwork in glass focused on the translation of the drawn image into/onto glass and ceramic objects via the printmaking processes. The prime objective in this translation is to render the spontaneous drawn image into a permanent material and thus create a celebratory 'fixing' of the moment (that the image was made) into a material object. My research has developed a number of printmaking approaches to do this, including 'integrated glass printing,' which utilizes the industrial print process flexography with kiln-formed glass techniques (Petrie 2006a).

This paper considers some examples of creative glass practice and research at the 'overlap' of these two distinct sectors of art and design-'glassmaking' and 'printmaking'. This is linked to previous research into creative glass in relation to 'materials and process', 'overlapping sectors', and 'combining the tacit and virtual' (Petrie 2007), It also builds on Petrie (2010a) and Petrie (2010b), which provided examples of how a willingness to 'blend' subjects in art and design education might offer the catalyst and context for innovation and creativity, with a focus on glass and print.

After a summary of the history and context of glass and print, this paper considers some of the developments in the use of glass and print over this period, including reference to students and colleagues of mine at the University of Sunderland. This includes some case studies, from this strand of visual art, where printed images and the glass surface or form are combined in artworks to convey ideas, articulated through a juxtaposition of printed image (pictures, pattern or text) and the glass form.

The unique properties of glass mean that printed imagery can be applied on the glass surface, encapsulated within the glass form, and even be made of glass. The case studies are divided into these three broad areas.

\section{Historical Background}

The crossover between the two separate creative areas of 'Glassmaking' and 'Printmaking' can be traced back to 18th century England and three petitions for patents made by the Irish engraver John 
Brooks, between 1751 and $1754^{1}$. Petitions for Patents were the first stage in obtaining a Patent and were often filed several months before the Patent was granted. Petitions are of especial interest when the application was unsuccessful, as is the case with Brooks, as they are often the only record of the applicants claim for having developed a new process. Brookes was not successful in his petitions, and it was not until 1781 that the first successful patent for printing onto glass was granted, to Henry Baker an enameller of Liverpool. In contrast to Brooks' petitions, Baker's patent gives considerable details of both the printing methods and inks used ${ }^{2}$.

The basic principle of all early printing for glass, enamels, or ceramic involved the transfer printing of images from engraved or etched copper plates, or sometimes wooden blocks, onto the surface of the ware. First the image would have been cut into the surface of the plate. This forms what is known as an intaglio plate. It would then have been inked up with ink containing an oil and enamel pigment. The surface of the plate was cleaned leaving the ink in the cut grooves that formed the image. The plate would then have been printed onto a tough thin tissue paper through a press. This paper, which is rather like the paper used to roll cigarettes, is known as 'potter's tissue' as it was more often used to print ceramics. After printing, the tissue was applied face down onto the surface of the ware and the back rubbed to transfer the image. The print was bonded to the form by firing in kiln.

Today, the Glass printing industry produces printed glass for a surprising range of applications. Screen-printed decoration allows for a broad range of effects and imagery to be applied to glass, for example, advertising and logos on tumblers, beer glasses, and perfume bottles. Advances in computer technology allow for the rapid design and production of decoration in full colour for different market demands. The field of architectural glass has seen growth in the use of printed images for windows, screens and building facades. But this paper focuses on what might be seen as a relatively recent strand of artists who are using glass and image for more sculptural or autonomous ends than the site-specific architectural glass artist.

Traditionally, printmaking has offered mechanical methods of reproducing imagery. For example, in the mass production of decorated 'Pyrex' cookware. For artists, methods like screen-printing allowed imagery to be scaled up for 'building sized' projects. It also allowed for photographic imagery to be transferred onto glass by direct screen-printing or transfers. More recently, a number of artists have been using more sophisticated printmaking methods in combination with 'digital' methods to make works that combine high levels of craft skills, which are supported by digital tools. This amalgam of digital tools, crafts skills and a combination of techniques might be seen as the key development in glass and print in recent years, and the following case studies reflect on this.

\section{Case Studies-Image on Glass}

When I first explored the cross overs between printing and glass in the early 2000's, when researching my 'Glass and Print' book, printing onto glass, which was then laminated, was a fairly common approach in architectural glass applications. Often these projects, such as building facades were designed by an individual, but then fabricated by companies that had the expertise and facilities for large-scale projects. This approach still continues, although the current economic situation may mean a reduction in large-scale public art projects. A recent example shows development in combining external fabrication with work undertaken by the artist designer. Rachel Welford is an architectural glass artist (and also PhD research at University of Sunderland). In a recent commission, 'St Peter's Chapter House Windows' in Sunderland, Rachel and fellow designer Adrian Riley combined screen-printed elements on the surface of glass with other glass decoration methods, such as sandblasting (Figure 1).

1 John Brooks. 1754. Documents held by The National Archives, Kew, UK. The first petition is in SP44-260, p. 513 and the second and third in SP44-261, pp. 55, 85.

2 Henry Baker. 1781. Patent no 1296. Baker's Specification. 'Ornamenting Glass'. 


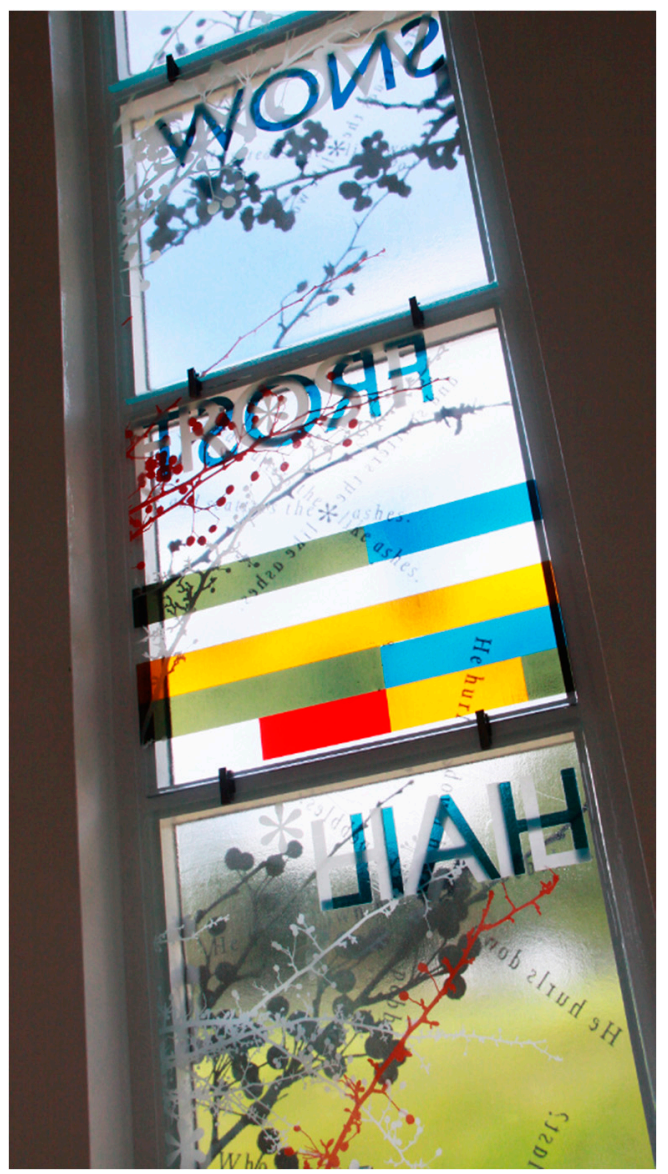

Figure 1. 'St Peter's Chapter House Windows' in Sunderland, Rachel Welford and Adrian Riley. 2017.

This series of twelve windows was inspired by 'The Reckoning of Time' by the Saxon monk known as 'The Venerable Bede'. Written in 725AD, this book is thought to be Bede's greatest scientific achievement and includes a 1253-year cyclical calendar, thereby creating the western calendar we still use today. Bede's observations of the changing seasons, tidal patterns, phases of the moon and the daily passage of time are celebrated in the imagery used in the windows. The trees and plants depicted in the design are thought to have grown around St. Peters monastery in Bede's time. A band of coloured blocks runs through the design to represent the mediaeval units of time-different to our own - that are explained at the start of the book. Welford describes a key aspect of the work:

Just as Bede observed the changes from day to night, the windows change with the light, revealing variations in pattern, shadow, reflection and colour at different times of the day and year and in varying weather conditions. Unlike most traditional stained glass they are also intended to be viewed from the exterior of the building as well as inside. (Welford 2018)

It is apt that this innovative piece is sited in this Saxon church as St. Peter's is recorded as the first building to have coloured glass in Britain. The windows are made up of two layers, the first glazed into the timber frames, making the building weather tight. This glass is a laminate, where a silver mirror has been screen-printed onto each glass sheet before lamination. The silver is only fully reflective when viewed through the glass and the top surface of the ink has a dull metallic appearance. To make the window show silver imagery on both sides, the imagery was screen-printed onto both sheets of glass and then laminated back-to-back. This printing process was undertaken by a fabricator, who delivered the glass to site, ready for installation.

The second layer of glass consists of fused panels, and these were created by Rachel Welford herself at the National Glass Centre/University of Sunderland Glass and Ceramics department. The 
seventy two panels that make up the twelve windows (six panels per window) are mounted onto the inside of the timber frames using steel fixings that were designed by the artists and cut using the water-jet cutter at The University of Sunderland.

The fused panels were in turn made up of three layers. The first (back) layer was water-jet cut glass, allowing intricate shapes of natural elements such as leaves, branches, flowers, waves on the sea, as well as text, to be cut out of vibrantly coloured glass. Next was a layer of clear glass that was screen-printed with coloured enamel. Lastly, another layer of clear glass was screen-printed, with a translucent white 'etch,' with an additive that increased the matt nature of the enamel when fired. This increases the contrast between high gloss glass surface and matt printed surface, creating interesting visual effects when the windows interact with light.

As the theme of this work relates to time the artists have cleverly designed the piece to interact with light, time of day and seasons. Welford describes these qualities below:

The silver mirror does interesting things with the light. It reflects the surroundings, bringing the environment into the artwork - the surrounding landscape becoming part of it. With strong backlighting, the mirror appears as a dark silhouette. This changes throughout the day and with varying weather conditions. The use of translucent printed 'etch' placed in front of the mirror layer allows the etch to effectively act as a projection screen. In direct sunlight, the mirror layer casts sharp shadows on the printed etch, but in overcast weather, the distance between the layers and the diffusing nature of the etch means that the mirror imagery appears soft and blurry. This transition is particularly effective in sunny/cloudy combinations, where sharp shadow imagery appears and then goes quickly whenever the sun disappears behind clouds. (Welford 2018)

So overall, this is a complex work that combines craft knowledge of hand-produced screen-printing on to the surface of glass, with glass kiln forming methods. In addition, aspects of the work are produced externally by a fabricator. The use of water-jet involves designing elements on the computer, which are then cut out in coloured glass with a high pressure water-jet and abrasive. Water-jet cutting may appear to be a rather straightforward and mechanical method, but in fact, this also requires great knowledge of the properties of glass and control of the cutting to avoid breakage.

My own take on printing onto the surface of glass was explored in work called 'China Sketchbook,' a piece using digital transfers onto glass (Figure 2). Sketchbook drawing is a passion, and to me forms a kind of visual diary. Sometime these images are translated into glass or ceramics as a way of fixing and commemorating the moment. This has included methods that I've termed 'integrated glass printing' (Petrie 2006a) and 'integrated glass drawing' (Cummings 2009). See the discussion of this below. The 'China Sketchbook' piece was developed when I was traveling in China to give lectures and meet prospective students. I kept a sketchbook on my I-Pad and these quick drawings that were made while traveling tell something of the life of a university professor while abroad: Taxis, airports, new cities, strange sites, down time in hotels, and meetings with colleagues. These images were emailed back to students and staff and also applied to glass to create a 'glass sketchbook' — a wall piece consisting of A4 sheets of Bullseye Glass, printed with digital prints of the I-Pad drawings. Each piece is wall mounted on 'angle hooks' nailed into the wall.

Before making this piece I has been ambivalent about digitally printed transfers. I felt that they had a quality of being facsimile of an original artwork. I had previously preferred to develop my own hand drawn and screen-printed transfers. However, the drawings produced on the I-Pad only existed as digital images drawn using the application, 'Paper'. The drawings were made by drawing with a finger onto the I-pad screen and the application created the coloured image. When these images were applied to white glass and fired, the resulting glass sheets had both the feel of the glass I-pad screen, as well as referencing a print onto paper. A white border around the image emphasized this connection to printing onto paper. So in this case, I felt that the digital image has a connection to how it was originally made and an integrity in relation to the overall work. 

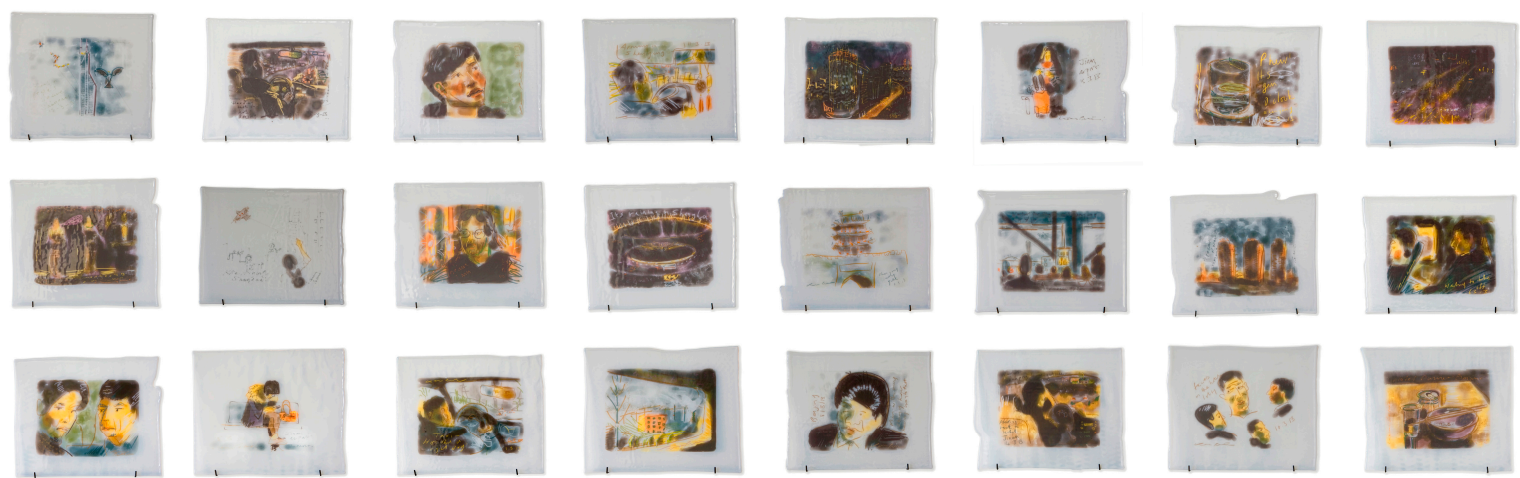

Figure 2. 'China Sketchbook' (detail), Kevin Petrie, 2013, Photo David Williams.

\section{Case Studies-Image in Glass}

One of the great qualities of glass is, of course, transparency, which means there is great potential to add printed imagery into glass forms. I explored this in some of my early glasswork in the 1990s. Other notable exponents have been Goshka Bialek in her 'Newspaper' sculpture, where screen-print imagery of figures 'float' inside a life sized female form (Petrie 2006b). The imagery was applied to glass ingots, and these methods, during the casting process, caused the imagery to distort and float inside of the glass.

Korean, Mikyoung Jung exploited the transparency and malleability of glass through combining screen-printed decals with cast glass (Figure 3). Her glass portrait busts, form a kind of 'every man' especially when she duplicates the cast heads and presents them together. But by encasing the images of printed texts inside of the heads, she offers a glimpse into the 'inner world' of her figures (Bruntnell 2009).

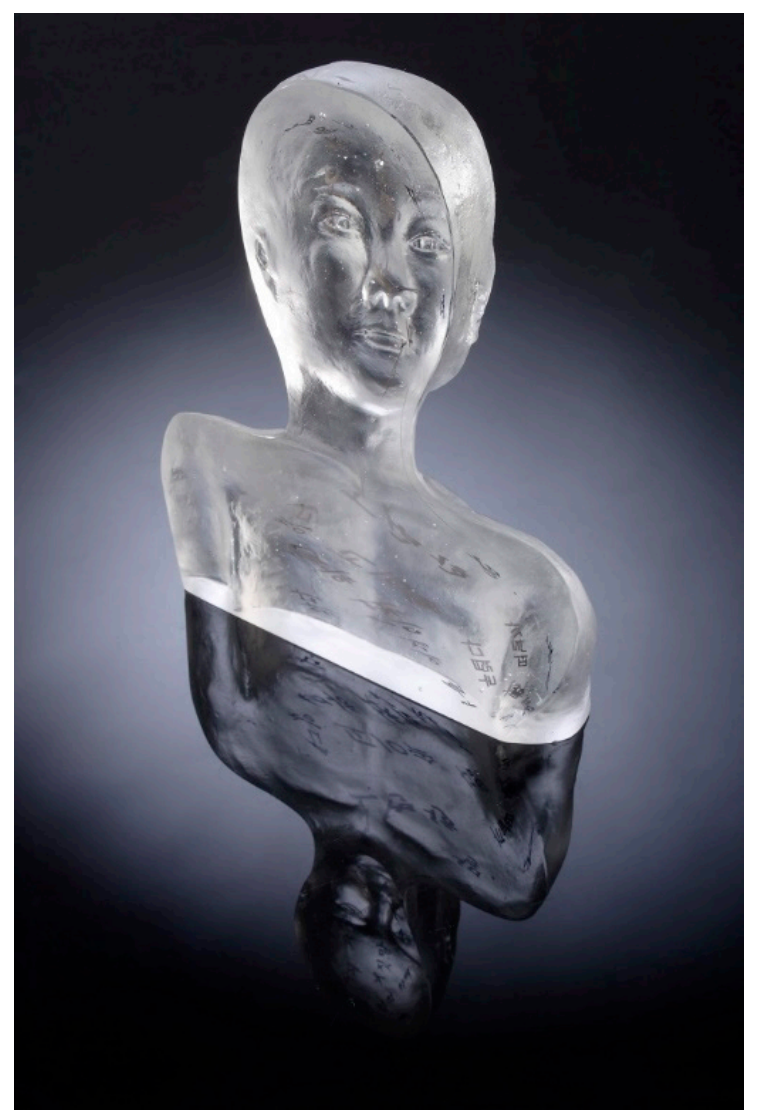

Figure 3. 'Head', Mikoung Jung, 2007. 
Glass casting is a process with a long history stretching back to Roman times and screen-printing is around one hundred years old. Combining the two processes together is relatively recent, but Mikyoung's real innovation was to use the Internet to gather the raw material for the texts that she used inside of the heads. She set up a website and asked visitors, "If you knew your thoughts and feelings would remain anonymous what would you say? Please write your true feelings about your life in general anonymously on this website".

Mikyoung recreated these personal responses as printed images reminiscent of 'ticker tape'. These strips of text were printed as decals in enamels that could withstand the high temperatures of the glass casting process. When cool, the glass heads were removed from the moulds and parts of the heads polished so that the viewer can look inside and read the texts.

Jeffrey Sarmiento from the USA is probably the most technically innovative exponent of glass and image working today. This is typified by his piece 'Ossify' and associated work, which combines aspects of ethnography, print, glass, water-jet cutting and glass carving (Figure 4). This piece emerged from a residency at Sunderland Museum and Winter gardens in the UK, which has an extensive ethnographic collection brought together by Edward Backhouse a 19th Century philanthropist. Sarmiento was invited by the museum to create a series of new works based on this collection. For 'Ossify,' he chose a wooden Maori paddle as the starting point. He also had unique access to the museums archive and collections and was able to view accession records. What he discovered through this was that many of the objects had contradictory written records relating to them. He was intrigued by how the museum creates a different context for objects.

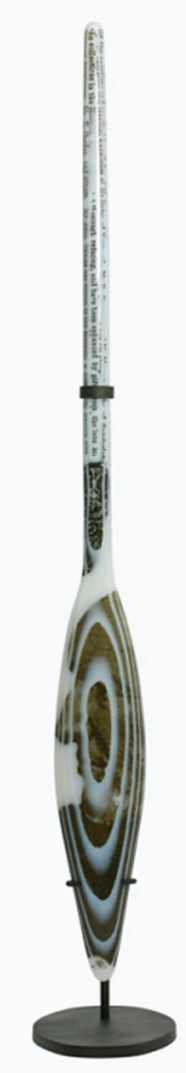

Figure 4. ‘Ossify', Jeffrey Sarmiento, 2009.

Sarmiento reproduced some of the accessions text, as well as a portrait of the collector Edward Backhouse, and screen-printed them onto sheets of glass. The prints were fired onto the glass and then stacked together to create a multi-layered 'sandwich' of glass and printed image. This stack 
was fused together in the kiln to create a solid block of glass with layered prints. This block was then cut into the shape of the Maori paddle using a water-jet cutter. This machine used a very high pressure jet of water with an abrasive to cut materials. Having achieved the basic shape of the paddle Sarmiento then hand-sculpted the paddle shape for grinding tool to achieve a more rounded form like the original paddle.

The sculpting of the glass form revealed the printed images within the layered thus creating both a sculpture and integrated image. By layering both the transparent and opaque white glass, the printed areas were protected and revealed with the form. Sarmiento calls his method 'EnthnoGraphic' glass, as he is trying to capture a kind of ethnography or picture of his experience of both working in the museum and living in Sunderland. This one work creates a blend of historical document, portrait (of Backhouse) and personal reflection.

Sarmiento is an innovator in many of his bodies of work and he discusses another, 'graphic swim' in this journal. In terms of glass and print developments, his piece 'Confluence' seems to me to represent an interesting addition to architectural approaches. 'Confluence' is a public glass artwork in Durham City Centre, UK (Figure 5). It was the winning bid among a selection of artists' proposals commissioned by and funded $(£ 30,000)$ by Carillion PLC, and realised in collaboration with Faulkner Browns Architects in design development.

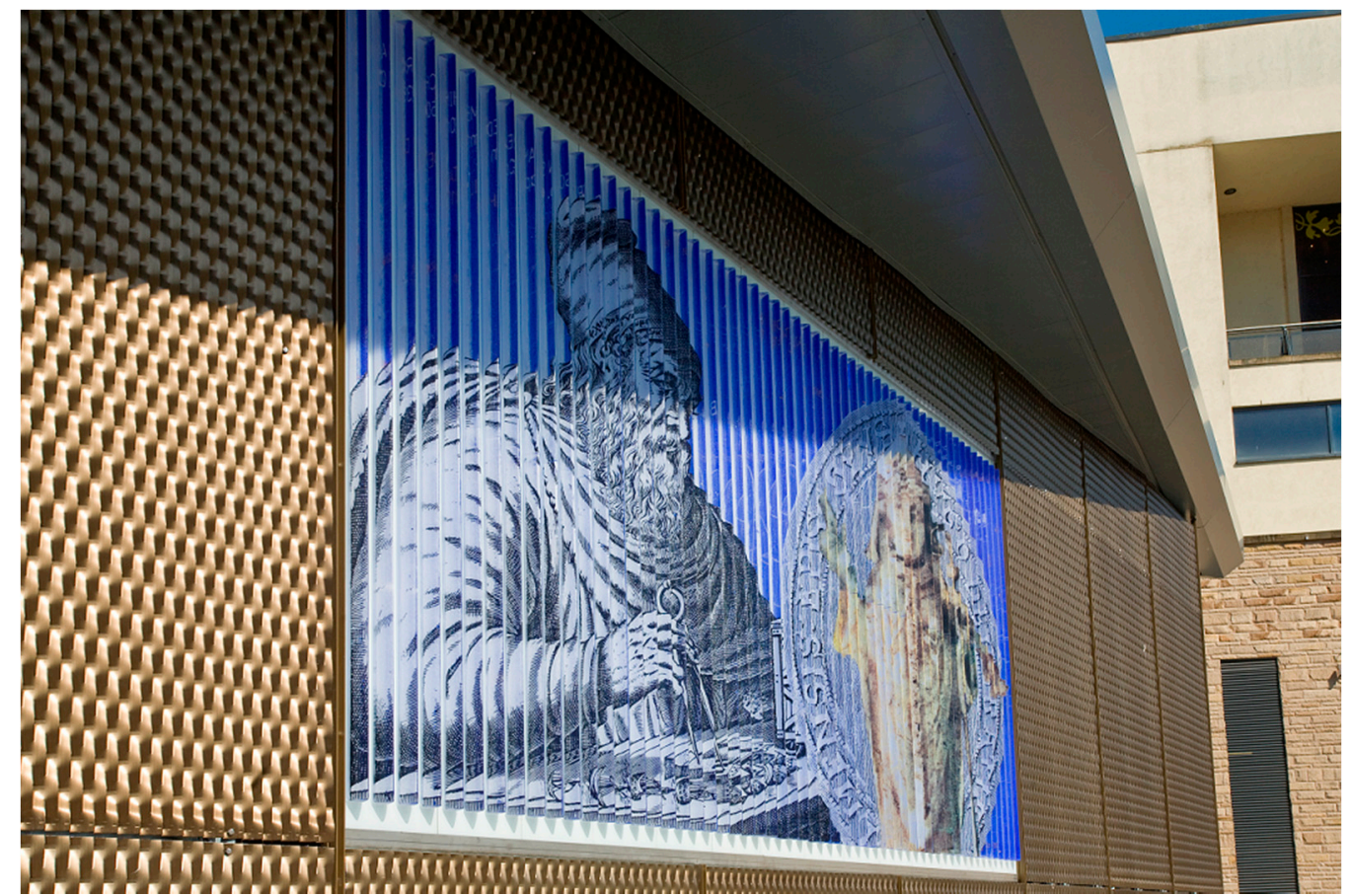

Figure 5. 'Confluence', Jeffrey Sarmiento, 2018.

The site sits on the River Wear and once housed a mill, and therefore, has been drawing on the river as a resource for 1000 years. The newly designed Archimedes screw provides a fish-friendly passage, as well as sustainable energy production for the government-building complex. However, it is difficult to see the screw in action, due to a metal housing placed on it for safety.

The artwork 'Confluence' consists of two key components to decorate the façade of the power station associated with the screw. Layers of fused printed glass refer to the monastic, industrial and social history of the site. The second element is a $2 \mathrm{~m}$ high glass design, based on a lenticular stereoscopic image, created using screen-printed and kiln formed glass prisms. It is innovative in that it builds on the use of multiple layers of coloured half-tone screen-prints to create a lenticular image, visible through the clear glass. To create such a work at a large scale, the two images (one of the technical drawing of the screw, the second of the history of bishops and patronage) have been segmented into 54 
individual prism-shaped fused glass elements, so that the printed images is embedded into the glass. This 'lenticular' approach is innovative in that two images can be seen depending on which direction the work is viewed from. Part of a redesigned river walk area, and prominently visible to pedestrians and drivers from nearby, and across the water, one set of fused glass panels is a panoramic portrait of the Bishop Mill's history.

\section{Case Studies-Image of Glass}

The approaches discussed above involved imagery printed onto glass at some point with ceramic type enamels in ink. Some practitioners have also been exploring using print or print-related methods just with glass - thus forming pieces in which the image is 'of glass'. I explored this in an artwork titled, 'St Pancras Moments,' made for the 'Glass Echoes 2' glass exhibition in the crypt of St Pancras Church, London. For this piece, I made a series of glass prints/drawings in kiln-formed glass. The method used can be seen as a blend of glassmaking with the 'dry point' printmaking process. Flat sheets of mould-making material are drawn in with a sharp tool to create an image, which is depressed or 'intaglio'. These drawn lines are then filled with black glass powder as one would 'ink' up an engraved metal printing plate. Clear glass granules are then applied on top of this, and the whole piece is heated in a kiln. This fuses the glass together to create a sheet of glass with the image applied to the front. Unlike a conventional print on paper, where the ink 'sits' on the surface of the paper, this glass print is composed entirely of glass. The glass and the print are one-forming a combined object and image.

In 'St Pancreas Moments,' this technique is used to translate images or 'snapshots' of the crypt and surrounding area of the church into glass (Figure 6). This celebrates and commemorates what might be seen as banal or forgotten spaces and moments. For example, an empty coffee cup left by a passerby, broken pieces of memorials to the dead left abandoned, someone walking down the road in front of the church, the artist's foot just in the 'frame' of the image, corners, a plug socket or a flower in bloom.

Kathryn Wightman (a PhD graduate for the University of Sunderland) has explored a variety of methods for the reproduction of photographic images and patterns including stripes, geometrics and floral designs in a range of colour palettes. She combines imagery and glass to produce both two-dimensional and three-dimensional forms.

Wightman has produced numerous bodies of artwork over the last ten years combining a diverse range of imagery with glass, and a notable feature in her work is the strong narrative element. The imagery she uses helps to engage the viewer in her story and it aims to evoke some form of response. A strong theme throughout her work is the use of pattern. When designing patterns for her work, Wightman takes inspiration from the world of fashion and textiles, often from previous decades. Although she uses the key elements of the patterns, she then updates them to give them a modern contemporary twist. This often results in a feeling of nostalgia for the viewer.

There are a number of reasons why Wightman feels glass is the ideal medium for displaying her decorative imagery. She believes glass offers the potential to layer the imagery, thereby adding a feeling of depth to her work. Blown glass techniques can be used to encapsulate the imagery into three-dimensional forms and this acts as a method of preserving the imagery. It also adds intrigue to the work. The optical qualities of the glass can be used to distort the imagery, thereby adding movement to the work.

'A little bit of lace' (Figure 7) gives a familiar object a new and unexpected perspective. It was a technical challenge that involved screen-printing powdered glass directly onto a kiln shelf then melting it together to form a lace like stencil. The process pushes the boundaries of the application of the material and adds a delicate sensibility to the glass, resulting in a beautifully tactile object, rich in texture. The innovation here is that, if the glass is analogous to ink, it is possible to create a print without applying it to a substrate as in printing onto paper. Here the 'ink' (i.e., the glass) and substrate (i.e., the support) is one and same. Essentially the 'image' has 'formed' the object. 

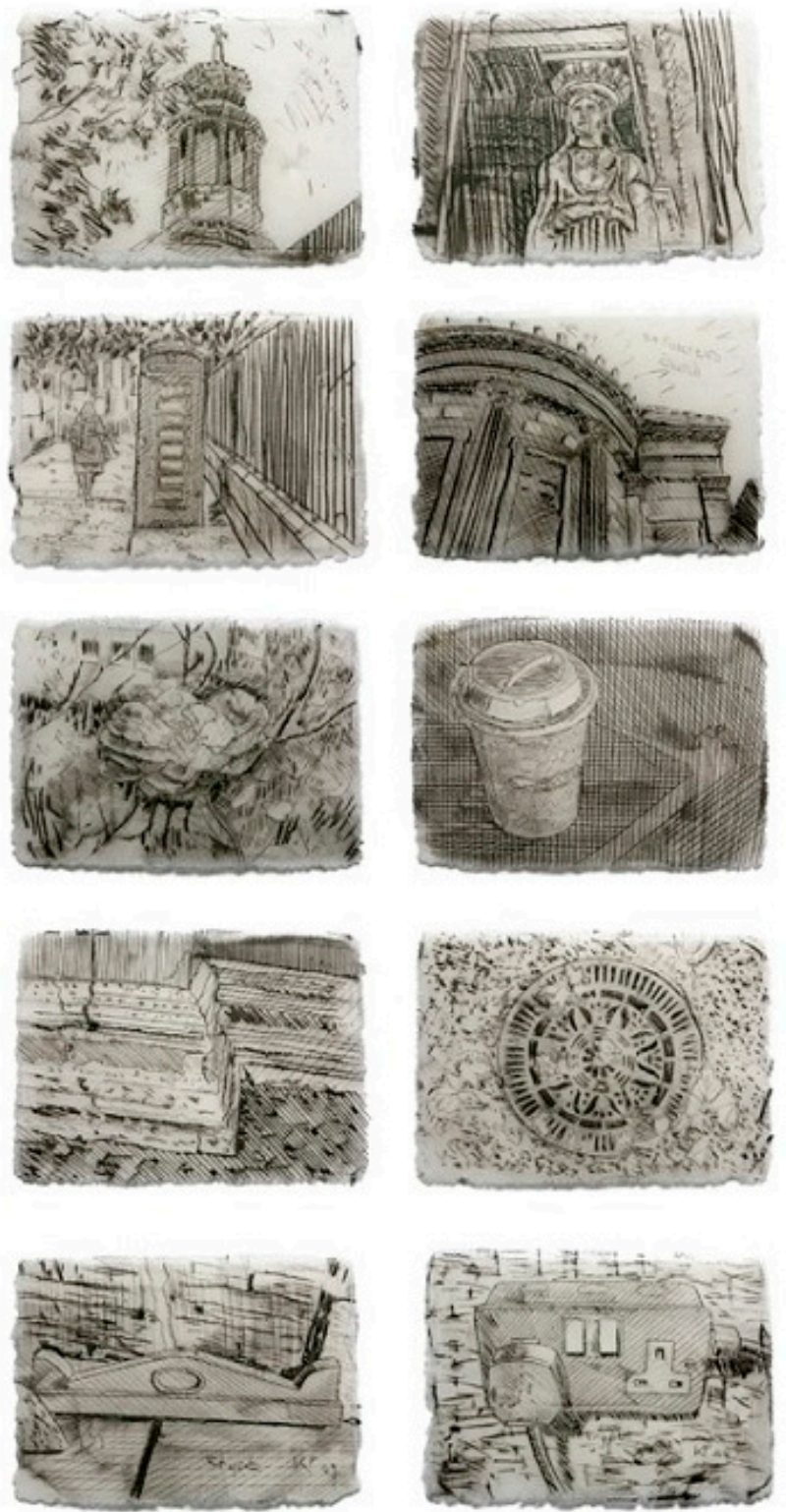

Figure 6. 'St Pancras Moments', Kevin Petrie, 2009.

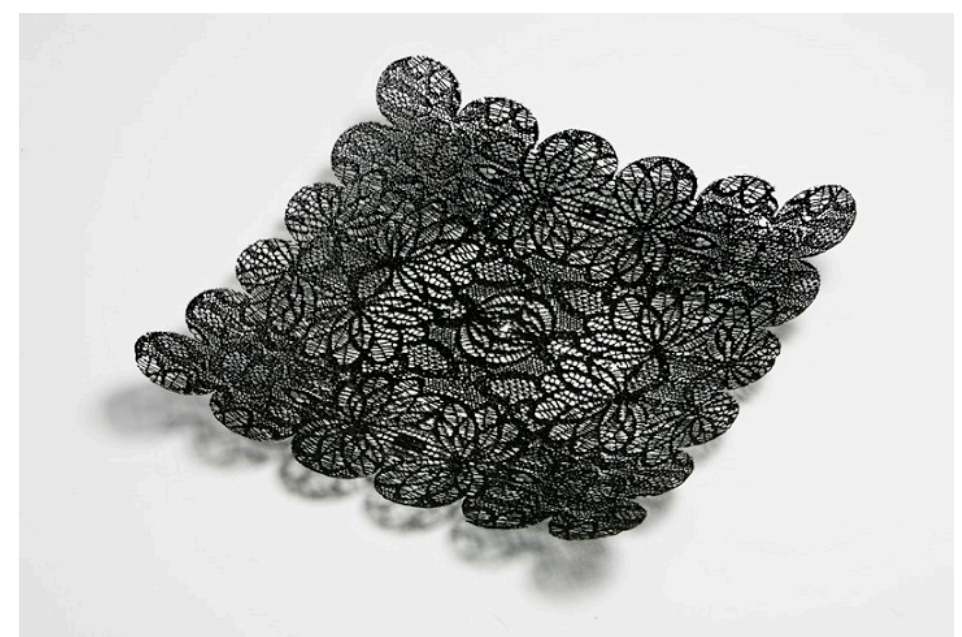

Figure 7. 'A little bit of lace', Kathryn Wightman. 2010. 
Wightman describes her more recent practice as:

An interpretation of human experience expressed through distortion and the manipulation of printed imagery and pattern.' Recent works consider aspects of identity and motherhood, specifically an internal struggle to find a new 'normal' in an idealized society. The work challenges the viewer to consider the ideals that we place upon ourselves, as well as the consequences of those ideals to our own existence in the world. Image and pattern play a pivotal role in Wightman's compositions and she draws from the floral and the decorative as a means of expressing her narratives. The nature of the printmaking and glassmaking processes she combines, results in intensely controlled methods. Yet the outcomes present an element of surprise. It is this balance of control and chance that pushes her forward in the exploration of idea, material, surface and form. (Wightman 2018)

Wightman's work increasingly blends the digital with high levels of craft skill. She also successfully brings the 'hand' of the maker into her works, which often disrupts the precise technique to add another layer of meaning. Images and patterns are generated digitally, and differing visualisations are trialed as a means of exploring and developing ideas. Software such as Adobe Illustrator is used to break the imagery down into separate layers for each colour. Each layer represents a layer of colour that will be screen-printed using glass powders onto a base layer of sheet glass. Sometimes the compositions can have up to fifteen or more layers depending on the complexity of the visual message. These layers of powdered glass 'ink' are then fixed through heating in the kiln.

The digital process acts as a tool that allows key aesthetic decisions to be considered, tested and resolved, before moving to the printing process and the use of costly materials. This saves glass material, wastage and time. However, for Wightman it is not enough to design her works virtually on a computer. The physical printing process and her mastery of this allow her to 'bridge the gap between the works existing in a virtual or physical space' (Wightman 2018). The knowledge of print processes is not enough, as she also needs to understand the materiality of the glass powder and how it will react during both printing and firing. Once the layers of the composition are designed, they are exposed onto a silkscreen to form stencils. The set-up involves great precision to ensure each printed layer aligns with the next in order to complete the overall image. The difficulty of this should not be under-estimated, as multi-colour printing with powder as an 'ink,' is a much more challenging proposition than using a conventional wet ink. This is due to the risk of disturbing the printed imagery mounts as each fresh layer is laid down. Wightman believes that 'the printing process allows me to turn the spark of the idea into something tangible, using my own hands, skills, aesthetic, and vision'.

More recently in her practice, Wightman has exploited the delicate nature of the unfired glass powder and explored 'the dichotomy of control and chance' in order to express a particular concept. For example, some pieces represent carpets and make the viewer think about domestic spaces and associated memories. In the pieces 'Carpet' and 'Stained,' Wightman makes careful coloured powder prints of carpet designs. But before fixing the design through the firing process, she introduces a 'distortion' into the design. In carpet, she walked over the piece barefoot, which after firing, resulted in a ghostly trace of footprints (Figure 8). In 'Stained,' she threw a cup of tea onto the printed glass powder to leave a fired 'stain' in the resulting work (Figure 9). These pieces are successful in several ways in my view. Firstly, a combination of print and glass powder allows for a compelling and convincing reproduction of a carpet. The glass powder is fired at just the correct temperature to create a matt textured surface to mirror carpet fibers. The design of the carpets is: 


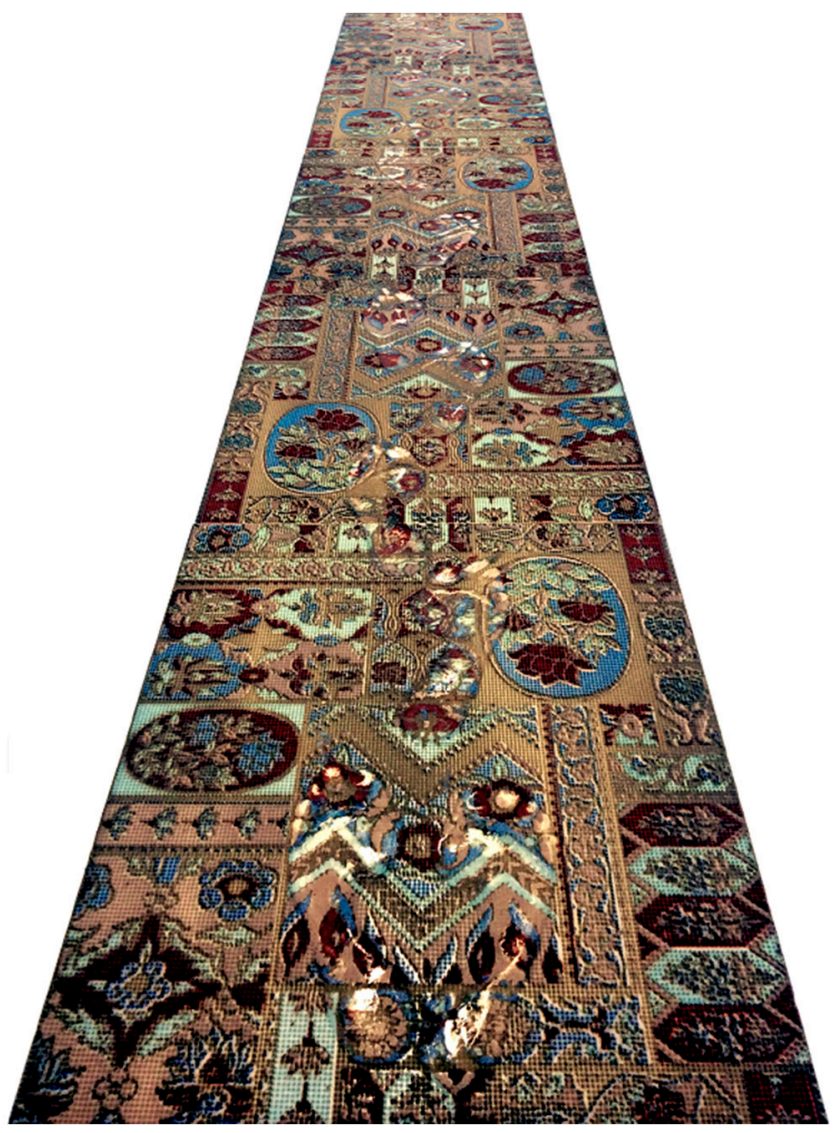

Figure 8. 'Carpet', Kathryn Wightman, 2014.

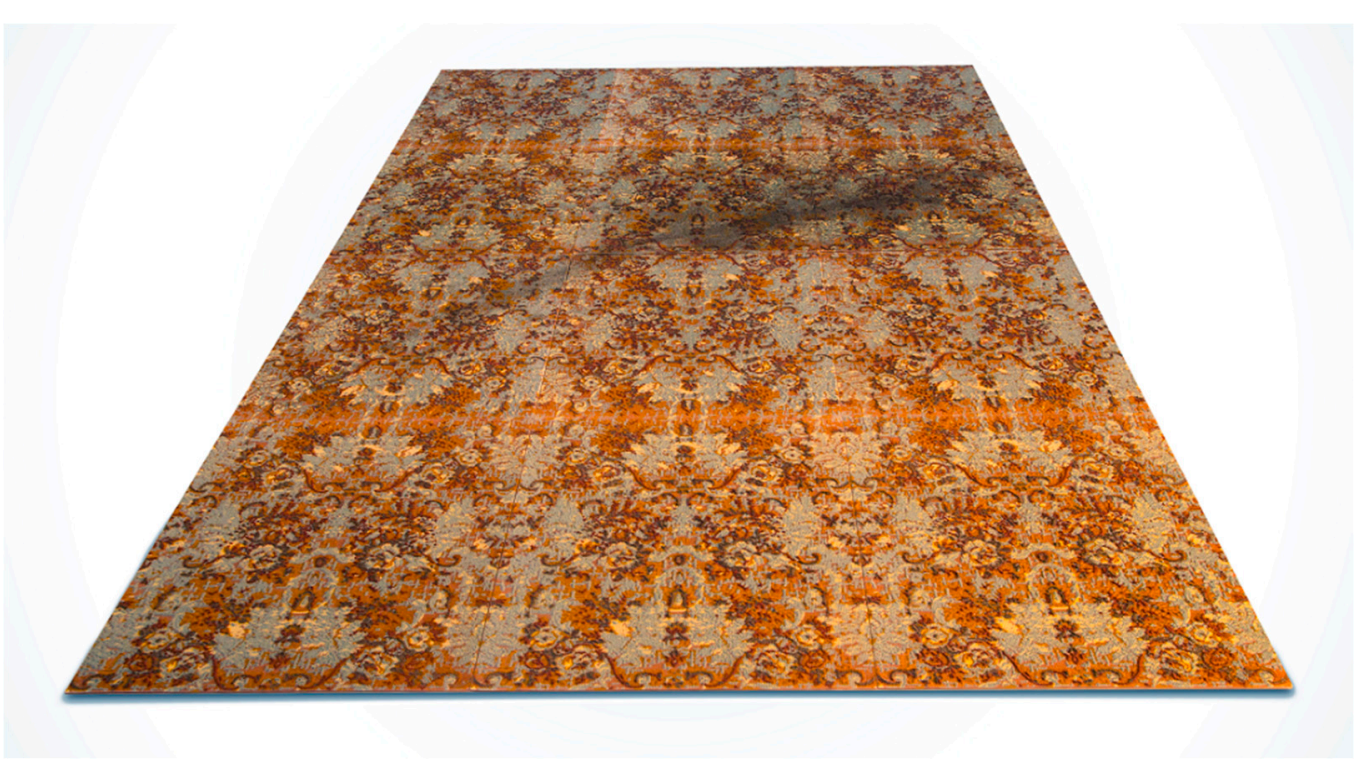

Figure 9. 'Stained', Kathryn Wightman, 2015.

What one might call 'retro,' adds to the feeling of nostalgia and memory. The translation of the carpet into glass translates the mundane carpet into an object of contemplation-an artwork. The ghostly interventions of the stain and footprint seem like an echo of the past or a trace of something that happened. Combined, this seems like a perfect match of material, process and idea. 


\section{Conclusions}

This paper offers some case studies of some of the developments in the combination of glass and printmaking. These examples are not exhaustive and certainly do not represent an overview of developments worldwide. However, the examples discussed represent a kind of 'convergence' in glass art, in which craft skills are increasingly being blended or combined with external fabrication or machine making methods. The digital and haptic also seems to be increasingly blended in making. This makes me think of David Pye's discussion of the 'the workmanship of certainty and the workmanship of risk' (Pye 2015). Although David Pye's classic text was written fifty years ago and does not directly comment on glass, it does offer some useful positions for today's glassmakers. Firstly, Pye offers a clear possible definition of craftsmanship-'workmanship using any kind of technique or apparatus, in which the quality of the result is not pre-determined, but depends on the judgment, dexterity and care which the maker exercises as he works'. He points out that in this kind of workmanship, there is always an element of risk in the making process. Glassblowing or kiln forming might be examples of this. This is in contrast to 'the workmanship of certainty', which might be found in factory production for example. The duality of approaches discussed by Pye, 'risk and 'certainly', might also be interesting to consider in relation to contemporary making methods that combine digital and machine methods, water jet cutting of glass for example, with more 'hands on' making methods, like glass blowing. The consideration of the element of 'risk' and the need for 'judgment, dexterity and care' in digital craft methods might be overlooked. One might think of screen-printing onto glass as being relatively straightforward, with an element of 'certainty' but when combined with other methods as in the work of Welford and Sarmiento above, the risk of failure increases. This is especially the case in Wightmans work where fine glass powder is printed and the image is very vulnerable to damage until firing. Also Wightman adds to the risk by deliberately 'damaging' the image by walking on it or throwing liquid at it. She makes an artistic virtue of the certainty/risk tension.

In summary, it seems as if the combination of print with glass is starting to firmly enter the canon of available methods for glass artists and when used in combination with other approaches, has great potential on, in, and of glass.

Funding: This research received no external funding.

Acknowledgments: Many thanks to the artists discussed in this paper who have kindly provided information and images.

Conflicts of Interest: The author declares no conflict of interest.

\section{References}

Bruntnell, Simon. 2009. Object of Desire. Metro Manila: Northlight Studio.

Cummings, Keith. 2009. Contemporary Kiln-Formed Glass. London: A\&C Black.

Ivins, William Mills. 1988. How Prints Look. London: John Murray.

Petrie, Kevin. 2006a. See-through prints: Glass Printing. Kevin Petrie describes a range of new methods for combining printmaking with powdered glass. Printmaking Today-International Magazine of Contemporary Graphic Art 15: 20-21.

Petrie, Kevin. 2006b. Glass and Print. London: A\&C Black.

Petrie, Kevin. 2007. Parallels and Connections: Emerging Trends in Ceramics and Glass Design Research. Paper Presented at International Association of Societies of Design Research Conference, Hong Kong, November 12.

Petrie, Kevin. 2010a. Creative glass research: Case studies from art and design. European Journal of Glass Technology, Part A 52: 1-10.

Petrie, Kevin. 2010b. Glass and print: Blending approaches for innovation in creative glass. In Creativity and Innovation in Glass. Proceedings of the International Glass Symposium. Wolverhampton: University of Wolverhampton.

Pye, David. 2015. The Nature and Art of Workmanship. London: Bloombury. 
Welford, Rachel. 2018. Email Communication with the Author. December 5.

Wightman, Kathryn. 2018. Email Communication with the Author. November 27.

(C) 2019 by the author. Licensee MDPI, Basel, Switzerland. This article is an open access article distributed under the terms and conditions of the Creative Commons Attribution (CC BY) license (http://creativecommons.org/licenses/by/4.0/). 